\title{
Do signo à construção: o legado saussuriano e as abordagens construcionistas da gramática
}

\author{
Priscilla Mouta Marques ${ }^{a}$ \\ Karen Sampaio Alonso ${ }^{b}$ \\ Diogo Oliveira Pinheiro
}

\begin{abstract}
Resumo
A importância das proposições de Ferdinand de Saussure, apresentadas no Curso de Linguística Geral (CLG), para o estabelecimento dos pilares da dita Linguística Moderna é consenso entre os estudiosos da linguagem. Apesar disso, na literatura há pouco ou nenhum reconhecimento dos ecos das reflexões gramaticais do CLG sobre o modelo teórico da Gramática de Construções (GC), desenvolvido nos Estados Unidos no fim do século XX. Tendo isso em vista, este artigo propõe-se a: (i) mostrar de que maneira a GC oferece um caminho eminentemente saussuriano para a superação do hiato deixado pelo CLG no que tange ao tratamento da criatividade sintática e (ii) mais amplamente, avaliar a convergência - e eventuais divergências - entre a GC e o modelo gramatical esboçado no CLG. Espera-se, com isso, contribuir para uma reavaliação da extensão do legado de Saussure sobre a teorização gramatical contemporânea, reconhecendo-o como um (improvável?) precursor da Gramática de Construções.
\end{abstract}

Palavras-chave: Signo linguístico. Sistema. Construção gramatical. Rede construcional. Gramática de Construções.

\footnotetext{
a Professora do Departamento de Linguística e Filologia e do Programa de Pós-Graduação em Linguística da Universidade Federal do Rio de Janeiro. Membro do Grupo de Estudos Discurso \& Gramática; E-mail: pmouta@gmail.com.

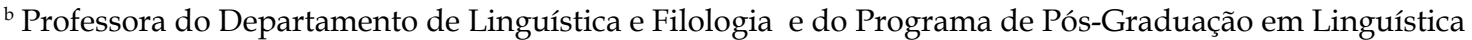
da Universidade Federal do Rio de Janeiro. Membro do Grupo de Estudos Discurso \& Gramática; E-mail: karensampaio@letras.ufrj.br.

c Professor do Departamento de Linguística e Filologia e do Programa de Pós-Graduação em Linguística da Universidade Federal do Rio de Janeiro. Membro do Laboratório de Linguística Cognitiva (LinC); E-mail: diogopinheiro@letras.ufrj.br.
} 


\section{Introdução}

Oimpacto do pensamento saussurianono desenvolvimento dos estudos da linguagem contemporâneos tem sido amplamente reconhecido em diversos campos, da Análise do Discurso à Aquisição da Linguagem, passando por áreas como a Semiologia e o Interacionismo Sociodiscursivo. Nesse cenário de celebração - e, sobretudo, avaliação - do legado saussuriano, causa alguma surpresa a quase completa ausência de referências às relações, por vezes surpreendentemente íntimas, entre a sofisticada reflexão gramatical do Curso de Linguística Geral (CLG) e o modelo teórico conhecido como Gramática de Construções (GC), que se desenvolveu a partir dos anos 1980 nos Estados Unidos. Os poucos estudos que mencionam essa aproximação entre as duas propostas a mantêm circunscrita ao paralelo entre as suas unidades de análise (GOLDBERG 1995; 2006; DIESSEL, 2015; TROUSDALE, 2013) - a noção de signo linguístico e a de construção gramatical.

Tendo isso em vista, o presente artigo pretende discutir os entrelaces teóricos da perspectiva saussuriana com o modelo da Gramática de Construções em suas várias vertentes, bem como explicitar e debater eventuais divergências entre essas duas abordagens. Em decorrência, pretende-se demonstrar como a GC dissolveu oscilações do Curso no que tange à extensão do conceito de signo linguístico, delineada, mais especificamente, na tensão sintaxe-sintagma.

Para cumprir os objetivos traçados, será fundamental recuperar a notável relação entre a concepção saussuriana de língua como sistema de signos interdependentes (em oposição à fala) e a visão de gramática como rede de construções. A ideia de rede, tal como desenhada no modelo da Gramática de Construções, parece dar conta tanto de relações do tipo associativas, bem como das relações de combinação do tipo daquelas descritas no eixo sintagmático (para mais detalhes, ver DIESSEL, 2015), que se mostram imprecisas no Curso,

${ }^{1}$ Há controvérsias em relação ao fato de a abordagem saussuriana ser lexicalista. $\mathrm{O}$ fato de diversos estudos, porém, assim a considerarem, demonstra que há pontos mal resolvidos no Curso que levam a esta frequente interpretação. uma vez que a abordagem lexicalista ${ }^{1}$ de Saussure se baseia sobretudo na palavra. Vantajosamente, a noção de construção abarca pareamentos de forma e sentido que variam de mais lexical a mais esquemáticos, de mais composicionais a mais idiomáticos, incorporando, portanto, os exemplos clássicos de signo saussuriano (palavras), os exemplos acrescentados 
à noção de signo (sequências de duas ou mais palavras que formam um todo) e também aqueles que ficam de fora da língua (formações sintagmáticas complexas e produtivas).

Sendo assim, este artigo está organizado da seguinte forma: na seção subsequente à introdução será apresentada uma breve revisão da literatura crítica à abordagem saussuriana para a construção do conhecimento linguístico, com especial enfoque na concepção de língua como um sistema de signos e nas noções de sintagma e paradigma, que lançará luz sobre o que será discutido nas seções seguintes. Na seção Do Curso de Linguística Geral à Gramática de Construções, será exposto o caminho oferecido pela GC para a superação da lacuna deixada pelo CLG no que diz respeito ao tratamento da criatividade sintática. Na seção Saussure construcionista?, serão apontadas e debatidas as semelhanças entre os modelos teóricos aqui abarcados, bem como as diferenças entre essas duas abordagens. Em seguida, serão apresentadas as considerações finais e as referências bibliográficas.

\section{Saussure: sistema de signos}

Conforme mencionado previamente, esta seção pretende apresentar uma breve revisão da literatura crítica do Curso, no que diz respeito mais especificamente às tensões presentes na obra condizentes com o conceito de signo linguístico e, por implicação, com o conceito de língua como sistema de elementos interdependentes e com as noções de sintagma e paradigma. Reiteramos que os tópicos aqui abarcados servirão de ponto de partida para as reflexões e discussões apresentadas nas seções posteriores.

No que tange à noção de signo, Saussure (2006 [1916]) postula que este é uma combinação convencional e arbitrária de um significante ("imagem acústica") e um significado

${ }^{2}$ Embora tenhamos aqui citado o trabalho de Bouquet (1997), que analisa os manuscritos de Saussure, nos detivemos neste artigo a trabalhar com os postulados do pensamento saussuriano presentes no Curso de Linguística Geral, mais especificamente na edição 27, ano 2006. ("conceito"), sendo ambas as faces psíquicas e indissociáveis. Essa acepção, porém, não é a única presente na abordagem saussuriana. Bouquet (1997) ${ }^{2}$ afirma que:

Signo é empregado por Saussure, ao longo de suas aulas e de seus escritos, em duas acepções: de um lado esse termo designa a entidade linguística global composta de uma face fonológica e de uma face semântica; de outro lado, ele designa apenas a face fonológica. (p.228) 
A imprecisão de uso do termo signo como referência ao elemento linguístico global ou a uma de suas faces já era apontada no CLG. Nele, Bally e Sechehaye pontuam que esse termo geralmente designa a imagem acústica, sendo esta a responsável pelo sentido total do referente. Nas palavras dos autores, "esquece-se que se chamamos a arbor signo, é somente porque exprime o conceito 'árvore', de tal maneira que a ideia da parte sensorial implica a do total" (SAUSSURE, 2006 [1916], p.81). Esta asserção destaca o peso diferenciado dado muitas vezes à imagem acústica em relação à face conceptual do signo e o reconhecido deslizamento terminológico presente na obra em questão. Tal deslizamento também se faz notório quando uma terceira acepção de signo é aventada no próprio Curso, abarcando sequências de palavras, como podemos verificar na seguinte passagem: "Via de regra, não falamos por signos isolados, mas por grupos de signos, por massas organizadas, que são elas próprias signos" (SAUSSURE, 2006 [1916], p. 149). Esta afirmação acarreta uma imprecisão sobre as linhas limítrofes do referido conceito - embora em diversas passagens seja utilizado como sinônimo de palavra, em outras se choca com a noção de sintagma.

Intrinsecamente relacionado à noção de signo está o conceito saussuriano de língua, configurada como a parte social da linguagem. Holdcroft (1991) ressalta que, segundo Saussure, "um estado de língua é um sistema de signos socialmente constituído, os quais são arbitrários e os quais podem ser definidos apenas em termos da sua relação com os demais dentro do sistema". Reside nesta definição a importância para o pensamento saussuriano do valor dos elementos no interior do sistema linguístico, sendo a língua, em outras palavras, entendida como "um sistema em que todos os termos são solidários e o valor de um resulta tão somente da presença simultânea de outros" (SAUSSURE, 2006 [1916], p.133). A relevância tanto da noção de valor quanto da de sistema é destacada por Hudson (2007) em sua Word Grammar, ao afirmar que esta definição de língua como um sistema de elementos interconectados é o prenúncio da visão de língua como rede, visão esta aceita por diversas abordagens teóricometodológicas modernas, em oposição à ideia de que a língua seria um inventário de entidades desconectadas. 
Akari (2015) reforça que a noção de valor, em termos saussurianos, se dá na relação de oposição entre palavras, a qual se desenvolve em dois domínios, sendo um deles o das relações sintagmáticas. Aponta o entendimento de que Saussure inclui no rol dos sintagmas sequências de duas ou mais unidades com alguma conexão entre elas ou com o todo e ressalta que essa 'combinação de dois ou mais elementos' abarca tanto palavras complexas (como, por exemplo, a palavra latina magnanimus), como expressões como s'il vous plait, no francês. $\mathrm{O}$ autor destaca, ainda, a asserção de Saussure de que relações sintagmáticas (ou sintagmas) pertencem tanto à língua quanto à fala (AKARI, 2015).

Akari (2015, p.7) conclui, citando Saussure, que

É na sintaxe que se encontra certa vagueza sobre o que é dado na língua e o que é deixado para a iniciativa individual. A delimitação é difícil de ser estabelecida. Deve-se admitir que aqui no domínio da sintaxe o elemento social (língua) e o elemento individual (fala), execução e associação fixa são como entremeadas, tornando-se mais ou menos entremeadas.

Tendo em vista o que foi dito até agora, vislumbra-se que uma das tensões do Curso reside exatamente na relação entre as dicotomias língua-fala e sintagma-paradigma. Ora, uma vez que a língua se dá na interseção dos eixos paradigmático e sintagmático, uma concepção primordialmente lexicalista de signo é, no mínimo, intrigante. Afinal, em que medida será possível dar conta de formativos sintaticamente complexos, sem romper minimamente com a visão tradicional de signo? Esse sem-lugar da sintaxe arrebanhou muitos críticos da perspectiva saussuriana.

Graffi (2001), embora reconheça que pouca atenção é dada à sintaxe na abordagem saussuriana, destaca, ao mesmo tempo, a importância das proposições do genebrino nas pesquisas em sintaxe que o sucederam. Considerando a dicotomia sintagma-paradigma, declara que a "sintaxe é (...) parte do eixo sintagmático, de acordo com Saussure: nem todos os fatos sintagmáticos são fatos sintáticos, mas todos os fatos sintáticos pertencem ao domínio sintagmático" (GRAFFI, 2001, p.170). Essa afirmação leva o autor a questionar, então, o que seriam os 'fatos sintáticos' no sentido saussuriano e a pontuar em seguida que "Saussure (...) estabelece que todos os tipos de sintagma 
'formados em padrões regulares' devem ser atribuídos à língua, não à fala. Por oposição, a sentença é considerada por Saussure como pertencendo à fala, não à língua" (GRAFFI, 2001, p. 170).

Em relação à posição de Meillet (1932) sobre o fato de que a sentença pertence à fala, por ser um fenômeno transitório e não um fato essencial da língua, o autor coloca que:

Possivelmente, a posição de Meillet não está relacionada apenas a uma interpretação parcial do pensamento de Saussure, mas também a uma forte dificuldade teórica de encaixar apropriadamente a 'sentença' dentro do escopo da língua: sentenças ilustram uma enorme variedade de padrões distintos, o que é difícil de conciliar com o um inventário de elementos bastante restritos, i.e., o 'código' constituinte da língua. Assim, foi mais fácil atribuir a sentença à atividade do indivíduo, i.e., à fala. (GRAFFI, 2001, p. 170)

Gordon (2006, p.81) faz uma revisão da crítica de Firth ao Curso e, no que tange à forte abstração do conceito saussuriano de lingua, afirma que

é paradoxal, sendo assim, à luz da vigorosa e firme objeção de Firth à abstração da língua, achar que ele [Saussure] caracterizou finalmente um conceito-chave no seu trabalho, o de significado colocacional, como uma abstração. 'Significado por colocação é uma abstração no nível sintagmático e não diz respeito diretamente à abordagem conceptual ou de ideia para o significado das palavras'. (grifo e inserção nossos)

Rizzi (2009), por sua vez, insere na discussão a questão da produtividade da sintaxe à luz de uma concepção de signo linguístico primordialmente lexical. Aponta a limitação que a noção de língua como inventário sistemático de signos apresenta, uma vez que, ao se pensar em um inventário, são deixadas de fora questões cruciais como a criatividade dos usuários da língua, exceto

por meio de alguma noção vaga de analogia: a infinita possibilidade de combinações de signos linguísticos que estavam, pelo menos em parte, relegadas à 'fala' por Saussure, atualização do sistema da língua em atos linguísticos individuais, e à 'língua', basicamente constituída por um repertório de idiomatismos fixos, não por uma sintaxe produtiva. (RIZZI, 2009, p.64)

O autor avança fazendo a ressalva de que, provavelmente, Saussure não estava satisfeito com essa conclusão, dadas as oscilações presentes no Curso. De acordo com Graffi (2001), a 
linguística do início do século XX não possuía um mecanismo formal para expressar a regularidade observada na sintaxe das línguas naturais.

Chomsky avança na crítica afirmando que:

Em qualquer evento, na medida em que a ordem das palavras é determinada por fatores independentes da língua, não é necessário descrevê-la como uma gramática particular ou universal (...). Vale a pena notar que essa visão ingênua da estrutura linguística persiste até os tempos modernos, de várias formas, na imagem saussuriana de uma sequência de expressões correspondendo a uma sequência amorfa de conceitos ou na caracterização comum da língua como uma mera questão de uso de palavras e sintagmas. (CHOMSKY, 1965, p.7-8)

Afastando-se claramente da tese saussuriana, Chomsky (1965), ao estabelecer a distinção entre competência e desempenho, defende que esta está relacionada à distinção entre língua e fala tal como propostas por Saussure, embora refute a ideia de que a língua seja meramente um inventário sistemático de itens e retome a concepção de Humboldt de "uma competência subjacente como um sistema de processos gerativos" (p.4).

Assinala-se, mais uma vez, que a noção de língua como um inventário sistemático e finito de itens acarreta a impossibilidade de tratamento da criatividade sintática dos falantes. Soma-se a isso a tensão presente no Curso em relação ao lugar da sintaxe: na fala, no nível da produção linguística individual, ou na língua, considerada no âmbito do eixo sintagmático. Assim sendo, conforme já mencionado, este artigo pretende apresentar uma possibilidade de dissolver essa tensão, partindo de uma abordagem construcionista da gramática, em que a unidade básica de análise - a construção gramatical - abarca estruturas que vão desde palavras (ou morfemas) a esquemas, incorporando tanto formações prototipicamente lexicais como também estruturas sintáticas abstratas do tipo SVO, por exemplo. Na próxima seção, será apresentado um maior detalhamento de como a proposta da GC é capaz de superar as limitações do Curso, principalmente no que tange ao tratamento da supracitada criatividade sintática. 


\section{Do Curso de Linguística Geral à Gramática de Construções}

Como vimos, a concepção de língua como sistema de signos não tem ficado imune a críticas. O problema aqui, conforme já discutimos, reside na dificuldade de conciliar a ideia de um inventário finito de elementos com a celebrada propriedade de infinitude discreta da linguagem humana. Em poucas palavras, o desafio pode ser formulado assim: como dar conta, à luz do modelo gramatical do $C L G$, das generalizações sintáticas que permitem ao falante produzir enunciados simultaneamente inéditos e gramaticais?

Nesta seção, argumentamos que a Gramática de Construções, modelo teórico desenvolvido dos Estados Unidos em fins do século $X X$, oferece uma saída para esse impasse. A fim de demonstrar essa tese, a seção se divide em duas partes. Inicialmente, procedemos a uma breve apresentação da abordagem construcionista. Na sequência, enfrentamos diretamente a pergunta que encerra o parágrafo anterior, procurando mostrar de que maneira uma teoria construcionista permite superar as limitações do modelo saussuriano sem abalar seus fundamentos epistemológicos.

\section{Do signo à construção}

Se a unidade básica da langue, no CLG, é o signo, a unidade básica do conhecimento linguístico, sob a perspectiva da GC, é a construção gramatical. Com efeito, a afinidade entre os dois conceitos não tem passado despercebida (DIESSEL, 2015; HOFFMANN; TROUSDALE, 2013): enquanto o signo é uma combinação arbitrária entre significante e significado, a construção é um pareamento convencional entre forma e função.

Note-se que ocorre aqui um movimento de dupla ampliação. De um lado, o termo "forma" abrange não apenas a forma fonológica (ou significante), mas também as formas morfossintática e prosódica. De outro, o termo "função" abrange não apenas a representação semântica (ou significado), mas também a função pragmática e propriedades discursivas. Com isso, chega-se a uma situação na qual todo signo é uma construção, mas nem toda construção é um signo. 
Assim, se exemplos inequívocos de signos, como morfemas e palavras, se qualificam como construções porque combinam uma representação fonológica a uma representação semântica -, o mesmo pode ser dito de elementos que prescindem total ou parcialmente de conteúdo fonológico. Aqui, temos em mente tanto padrões formulaicos semipreenchidos, do tipo LOGO SN ou ONDE QUE + SENTENÇA INTERROGATIVA ${ }^{3}$, quanto esquemas inteiramente abertos, como o padrão [s[vo]]. Do ponto de vista da $G C$, todas essas unidades podem ser representadas como pareamentos de forma e função, já que, paralelamente às informações formais (quer sejam fonológicas ou morfossintáticas), elas apresentam algum tipo de especificação semântica ou pragmática: LoGO SN expressa perplexidade diante de uma informação expressa anteriormente; ONDE QUE + SENTENÇA INTERROGATIVA expressa rejeição enfática a uma ideia recuperável contextualmente; e o padrão [s[vo]] evoca uma cena conceptual na qual um agente atua sobre um paciente.

Esses exemplos ilustram aquilo que a literatura construcionista tem chamado de continuum léxico-sintaxe. Essa expressão busca sintetizar a ideia de que o inventário de construções inclui (i) entidades inequivocamente associadas ao domínio do léxico, como palavras e morfemas; (ii) entidades inequivocamente associadas ao domínio da sintaxe, como padrões de estrutura argumental; e (iii) entidades que se situam no meio do caminho entre léxico e sintaxe, como as expressões semifixas que comentamos acima. À luz da $G C$, portanto, o conhecimento linguístico do falante será entendido como um vasto repositório de construções gramaticais de todos os tipos, das mais concretas/específicas (isto é, fonologicamente preenchidas) às mais abstratas/gerais (isto é, fonologicamente não-preenchidas). No jargão construcionista, esse repositório de construções tem sido referido pelo feliz neologismo constructicon - uma mescla lexical resultante da fusão entre as palavras lexicon ("léxico") e construction ("construção").

${ }^{3}$ Esses padrões licenciam, respectivamente, usos como "Logo o meu pai!" e "Onde que Saussure e GC não têm nada em comum?!".

\section{Uma solução saussuriana para as limitações do modelo saussuriano}

Apresentada a concepção de língua assumida pela GC, cabe retornarmos à pergunta inicial: de que maneira esse 
modelo permite superar as limitações do CLG no tratamento da criatividade sintática sem ameaçar, com isso, os pilares do pensamento saussuriano?

Em poucas palavras, o truque da GC consiste em abrir mão da ideia de que a unidade básica do sistema deve necessariamente exibir um significante. Com efeito, a definição propositalmente ampla (mas não vaga!) da noção de construção gramatical permite que se postulem, no próprio sistema linguístico, entidades que exibem tão-somente forma sintática - e não forma fonológica. É precisamente essa forma sintática que torna o modelo capaz de apreender fatos gramaticais como constituência (como em [s[vo]]) e ordem linear (como nas construções SV e VS). Ora, uma vez que se aceite que o polo formal das construções abstratas é o lócus de representação das generalizações sintáticas, a conclusão que se segue é inevitável: em uma visão de língua como sistema, o tratamento do conhecimento sintático exige que o sistema comporte entidades sem significante. É precisamente essa exigência que o conceito de construção gramatical permite satisfazer.

Ao mesmo tempo, é necessário reconhecer que essa mudança não implica qualquer tipo de rompimento epistemológico em relação à arquitetura gramatical sugerida no CLG. E isso por duas razões: (i) porque a abordagem construcionista preserva a ideia de que a unidade fundamental da língua é uma entidade de "duas faces", em que uma forma é diretamente pareada a propriedades não formais, e (ii) porque essa mesma abordagem mantém a concepção de língua como um sistema formado por unidades interconectadas - isto é, uma "totalidade solidária" (SAUSSURE, 2006 [1916], p. 132). Se é verdade que essa concepção é o insight fundamental do saussurianismo (ILARI, 2004; MATTHEWS, 2003), então a preservação da ideia de língua como sistema implica adesão aos fundamentos do pensamento saussuriano.

Neste ponto, é crucial ressaltar a diferença entre esse tipo de abordagem e a arquitetura do conhecimento linguístico assumida no âmbito da linguística gerativa. Como vimos, uma crítica que se faz ao pensamento saussuriano diz respeito à impossibilidade de explicar a criatividade sintática a partir de uma concepção de língua como sistema de signos. Na tradição chomskiana, a solução para essa dificuldade envolve a postulação de um componente adicional, de caráter gerativo, 
capaz de realizar sequências de operações derivacionais responsáveis por criar a estrutura sintática. Sob essa ótica, a gramática deixa de ser vista como um sistema de unidades entrelaçadas e passa a ser concebida como um mecanismo gerador de sentenças bem formadas.

A GC, por seu turno, oferece uma solução radicalmente distinta: em vez de capturar o conhecimento sintático por meio de um conjunto de regras ou derivações (isto é, processos), opta-se por capturá-lo por meio de construções abstratas (isto é, entidades). Como um sistema por definição conecta entidades discretas, essa opção é a única que permite preservar a ideia de língua como sistema.

É preciso reconhecer, no entanto, que certas partes dessa solução - bem como algumas de suas implicações teóricas mais interessantes - já podem ser entrevistas, de forma mais ou menos embrionária, no CLG. É para esse ponto que nos voltamos agora.

\section{Saussure construcionista?}

Muito embora a relação entre as noções de signo linguístico e construção gramatical tenha sido amplamente reconhecida na literatura construcionista, não deixa de causar surpresa o fato de que diversas outras afinidades (às vezes surpreendentes) entre a GC e o modelo esboçado no CLG ainda não tenham sido exploradas. Com efeito, como pretendemos mostrar nas próximas páginas, o pensamento gramatical desenvolvido por Saussure no início do século $X X$, em seus cursos de linguística geral na Universidade de Genebra, guarda semelhanças notáveis com o modelo construcionista que emergiu na década de 1980 na Universidade da Califórnia, Berkeley.

A fim de discutir e avaliar essas semelhanças, esta seção está dividida em cinco partes. Em cada uma delas, busca-se desenvolver uma comparação entre uma premissa teórica da GC e certas posições análogas que podem ser encontradas no CLG. O objetivo, em última análise, é o de avaliar o grau de sobreposição entre os dois modelos, identificando pontos de convergência, divergência e complementaridade. 
Premissa 1: A unidade básica da língua é a construção gramatical, definida como um pareamento convencional entre forma e função.

Essa premissa, evidentemente, ecoa a sugestão saussuriana de que a unidade básica da língua é o signo, entendido como um pareamento arbitrário entre significante e significado. Dado que a principal diferença entre as duas formulações já foi discutida na seção anterior, o mais importante neste momento é reforçar que essa divergência revela muito mais um aprofundamento do insight saussuriano do que qualquer tipo de rompimento em relação a ele.

Dito isso, é possível agora explorar a noção de convencionalidade, tipicamente presente nas definições de construção gramatical. Esta, como se sabe, está longe de ser uma ideia estranha ao pensamento saussuriano, para quem o signo linguístico repousa em um "hábito coletivo" - ou, mais simplesmente, uma "convenção" (SAUSSURE, 2006 [1916], p. 82). Tanto no CLG quanto no âmbito dos modelos construcionistas, o conceito de convencionalidade traduz a sugestão de que a relação forma-função reflete um acordo tácito entre membros de uma dada comunidade.

Pode ser instrutivo observar, no entanto, que o interesse no caráter convencional do signo/construção parece ter motivações distintas em cada uma das abordagens, compatíveis com os diferentes momentos históricos em que cada paradigma foi erigido. No âmbito do pensamento saussuriano, a ideia de convencionalidade está alinhada tanto à sociologia de Émile Durkheim, fundada sobre o conceito de "fato social" (DURKHEIM, 2012 [1895]), quanto à concepção sociológica de William Dwight Whitney, que enxerga a língua como instituição social. Nesse contexto, enfatizar o caráter convencional do signo é importante para assegurar a primazia do coletivo/social sobre o individual - o que está em consonância com a ideia de que o analista deve "situar a língua em seu quadro social e formular a questão como a formularíamos para outras instituições sociais" (SAUSSURE, 2006 [1916], p. 86), uma vez que "o signo linguístico escapa à nossa vontade" (SAUSSURE, 2006 [1916], p. 85).

No caso da GC contemporânea, contudo, essa discussão não se coloca. Aqui, o interesse pela convencionalidade 
emerge como uma reação à tendência da tradição chomskiana a conceber o conhecimento linguístico como um conjunto de princípios altamente abstratos. Na contramão dessa tendência, a GC tem alertado para o fato de que boa parte dos usos linguísticos cotidianos é formada por expressões préfabricadas, que funcionam como clichês léxico-gramaticais (DABROWSKA, 2014; FILLMORE, 1979). Sob essa ótica, saber uma língua consiste não apenas em conhecer construções abstratas, mas também em saber quais formas de expressão, dentre as alternativas bem formadas, são normalmente utilizadas pelos falantes nativos para expressar um dado conteúdo. Nesse contexto, enfatizar a natureza convencional da construção é uma maneira de chamar a atenção para a primazia dos aspectos idiossincráticos do conhecimento linguístico em detrimento dos princípios sintáticos altamente gerais.

É preciso reconhecer, no entanto, que, no $C L G$, a natureza convencional do signo é menos enfatizada que a sua natureza arbitrária. Diante disso, cabe perguntar o que a GC tem a dizer em relação ao debate arbitrariedade versus motivação. Em outras palavras: se o signo saussuriano é arbitrário, o que os linguistas construcionistas dizem a respeito da construção gramatical?

Caso nos concentremos sobre a vertente funcionalcognitiva da $G C$, teremos a impressão de que existe aqui uma divergência inconciliável. Afinal, pesquisadores alinhados a essa tradição teórica tendem a enfatizar o caráter (frequentemente) motivado das construções gramaticais - isto é, o fato de que a forma gramatical, embora não inteiramente predizível a partir da função, tampouco é completamente arbitrária (GOLDBERG; AUWERA, 2012; GOLDBERG, 2006; CHEN, 2003).

Interessantemente, porém, os dois tipos de motivação reconhecidos nessa literatura parecem ser precisamente aqueles que já podem ser vislumbrados no CLG. Com efeito, o caso residual das onomatopeias (SAUSSURE, 2006 [1916], p. 83) corresponde ao que alguns estudos construcionistas chamam de motivação externa - isto é, a possibilidade de que fatos extralinguísticos motivem a forma gramatical. Ao mesmo tempo, a famosa "motivação relativa" do CLG (SAUSSURE, 2006 [1916], p. 152-155) equivale ao que tem sido referido em GC como motivação interna - isto é, a possibilidade de que uma determinada forma do sistema motive uma outra forma a ela relacionada. 
O primeiro caso pode ser percebido, por exemplo, na sugestão de Chen (2003, p. 46) de que a ordem linear da Construção de Inversão Locativa do inglês (por exemplo, "Outside the door sat Tom Lopez") é motivada, em última instância, pela "fisiologia da percepção visual humana": argumenta-se que o ato de localizar uma entidade (no exemplo, “Tom Lopez") é facilitado pela apresentação prévia de uma outra entidade capaz de funcionar como ponto de referência (no exemplo, "the door"). Aqui, portanto, assim como ocorre com as onomatopeias discutidas por Saussure, a motivação emana do mundo extralinguístico, e não do próprio sistema. Com efeito, a analogia é tão exata que a mesma ressalva apontada no CLG em relação às onomatopeias se aplica ao problema da inversão locativa: assim como a forma exata de uma onomatopeia dependerá das propriedades internas ao sistema, a inversão locativa pode ser bloqueada mesmo quando existem fatores extralinguísticos que alegadamente a favoreceriam (como em "* $\mathrm{Up}$ the hill has been climbing my brother"; cf. Chen (2003, p. 173)). Nos dois casos, portanto, o que se verifica é que motivações extralinguísticas têm seu potencial de atuação limitado por restrições formais inerentes a cada sistema.

Interessantemente, também a "motivação relativa" pode ser flagrada na literatura construcionista, em geral sob o rótulo de "motivação interna". Ela comparece, por exemplo, na sugestão de que, na construção SUJ BE TO VINF (por exemplo, "The match is to begin at 11 pm"), o emprego de "to + infinitivo" para indicar futuridade é motivado pelo fato de que uma outra construção com "to + infinitivo" exibe orientação para o futuro (por exemplo, "He stopped to see her") (GOLDBERG; AUWERA, 2012). Neste caso, assim como ocorre com o onipresente exemplo de "dezenove" (SAUSSURE, 2006 [1916], p. 152), tem-se uma motivação de segunda ordem: embora, na construção subjacente a "He stopped to see her", a relação entre "to + infinitivo" e futuro seja arbitrária, uma vez que essa relação esteja estabelecida no sistema, ela permite motivar o valor de futuridade na construção sUJ BE TO VINF. Dito de outro modo, a motivação aqui emana não diretamente do mundo extralinguístico, mas de outros elementos do sistema.

Em suma, a unidade básica de análise da GC não é fundamentalmente diferente da unidade básica do modelo saussuriano. Além disso, enfatiza-se em ambos os casos - ainda 
${ }^{4}$ Em diferentes pontos do CLG, esses "tipos gerais" são referidos como "tipos de sintagmas" ("types de syntagmes"), "tipo determinado" ("type determiné"), "tipos gerais" ("types généraux"), "padrões regulares" ("patróns réguliers") e "tipo sintagmático latente" ("type sintagmatique latent").

${ }^{5}$ No texto original, os exemplos são "i mpardonnable",

"intolérable" e "infatigable" que por razões diversas - o fato de que a ligação entre os dois polos dessa unidade é convencional. Por fim, enquanto o CLG sublinha o caráter arbitrário do signo, a GC funcional-cognitiva tende a valorizar a motivação - mas esta é mais uma diferença de ênfase e interesses do que uma divergência substantiva.

\section{Premissa 2: As construções gramaticais podem apresentar diferentes graus de preenchimento fonológico}

Embora o signo saussuriano, diferentemente da construção gramatical, não possa apresentar diferentes graus de preenchimento fonológico, isso não significa que não haja espaço, no modelo do CLG, para entidades sem materialidade sonora. Aqui, iremos nos debruçar sobre um tipo específico de entidade dessa natureza: os chamados "tipos gerais" ("types généraux") (SAUSSURE, 2006 [1916], p. 145), entendidos como esquemas abstratos que resultam de generalizações sobre sequências concretas ${ }^{4}$.

No plano da morfologia, por exemplo, Saussure (2006 [1916], p. 145) observa que a palavra "indecorable" está associada a um "tipo determinado", o qual, por seu turno, "só é possível pela lembrança de um número suficiente de palavras semelhantes" 5 . De maneira análoga, mas desta vez no território da sintaxe, sequências particulares como "a Terra gira" se sustentariam sobre "tipos gerais", os quais teriam base na língua graças a "recordações concretas" (SAUSSURE, 2006 [1916], p. 145).

Mas o que exatamente seriam esses "tipos"? Embora o CLG seja vago a esse respeito, algumas conclusões parecem sólidas. Em primeiro lugar, o contraste entre os tipos e as "recordações concretas" sugere que os primeiros têm natureza abstrata - e, como se sabe, o termo "abstrato" ("abstraite"), no CLG, faz referência a entidades sem significante (SAUSSURE, 2006 [1916], p. 160-162). Ao mesmo tempo, o adjetivo "gerais" sugere que esses tipos são generalizações fundadas em exemplares concretos - o que significa que eles devem capturar tudo o que há em comum entre esses exemplares.

Se essa leitura estiver correta, a conclusão imediata é a de que os "tipos gerais" do CLG são notavelmente semelhantes às construções gramaticais (semi)abstratas. Com efeito, a GC tem enfatizado o fato de que essas construções são esquemas gerais 
construídos pelo falante a partir de exemplares concretos. A afinidade entre essa ideia e a sugestão de que "tipos gerais" repousam sobre "recordações concretas" é autoevidente.

É preciso, no entanto, sublinhar uma diferença entre as duas abordagens. Se a GC assume inequivocamente que as construções abstratas integram a rede construcional, o texto do CLG parece sugerir que esses "tipos gerais" não fazem parte do sistema linguístico. Essa posição pode ser entrevista, por exemplo, na sugestão de que os tipos "têm [...] base na língua sob a forma de recordações concretas" (SAUSSURE, 2006 [1916], p. 145). Essa formulação parece indicar que os tipos gerais não estão diretamente presentes no sistema linguístico - em vez disso, eles se conectariam ao sistema por intermédio dos itens e sequências concretos, estes sim efetivamente incluídos na langue.

A GC funcional-cognitiva não nega que encadeamentos particulares de itens, como "a Terra gira", possam figurar na rede construcional - pelo contrário, a hipótese é a de que sequências muito frequentes serão diretamente armazenadas na memória do falante (BYBEE, 2010; GOLDBERG, 2006). No entanto, convivem com essas sequências, como parte igualmente legítima do sistema, as abstrações criadas a partir delas. Nesse sentido, a GC parece se afastar, de forma relevante, da proposta saussuriana de que "não existe nada de abstrato na língua” (SAUSURRE, 2006 [1916], p. 145).

Premissa 3: As construções gramaticais estão interconectadas por diferentes tipos de links, formando uma rede construcional

Um dos princípios básicos da GC é o de que as construções gramaticais se apresentam entrelaçadas por meio de dois tipos de relações: os links horizontais, que associam construções com o mesmo grau de especificidade, e os links verticais, que associam construções com graus distintos de especificidade (DIESSEL, 2015). Como resultado, assume-se que o conhecimento linguístico do falante toma a forma de uma rede de construções interconectadas.

De saída, parece claro que a noção de rede construcional é em larga medida análoga ao conceito de sistema - trata-se, afinal, de um todo formado por partes interconectadas. Diante disso, vale a pena arriscar a seguinte pergunta: seriam os tipos 
de links propostos pela GC equivalentes aos tipos de relações entre signos do CLG?

À primeira vista, poderia parecer que a resposta é positiva - de fato, é tentador associar relação paradigmática a link vertical e relação sintagmática a link horizontal. Gostaríamos de sugerir, no entanto, que os fatos não são assim tão simples: as sobreposições entre as duas abordagens existem, e são robustas, mas menos claras e diretas do que essa associação faria supor.

Comecemos pelos links horizontais, que conectam construções como "galho" e "árvore" (graças a afinidades semânticas), "cá" e "pá" (graças a afinidades fonológicas) e "nadador" e "jogador" (graças a afinidades semânticas $e$ fonológicas). Aqui, restam poucas dúvidas de que estamos tratando das conhecidas relações paradigmáticas - conexões in absentia fundadas sobre associações morfológicas ("enseignement, armement, changement"), semânticas ("ensino, instrução, aprendizagem, educação") ou fonológicas ("enseignement e justement") (SAUSSURE, 2006 [1916], p. 145).

Os links verticais, por outro lado, não encontram correspondência direta no pensamento saussuriano, por uma razão simples: a postulação desse tipo de link pressupõe a existência de construções com diferentes graus de preenchimento fonológico ${ }^{6}$. Dado que o sistema linguístico, tal como delineado no $C L G$, não comporta entidades sem materialidade fonológica, não faz sentido reconhecer um tipo de link que associe unidades mais abstratas a suas materializações concretas.

E quanto às relações sintagmáticas? Não estariam elas de alguma maneira reconhecidas na arquitetura gramatical proposta pela GC? Certamente estão - mas não equivalem, como acabamos de ver, aos links horizontais. Na verdade, provavelmente em virtude da hegemonia das "gramáticas de constituência" na linguística norte-americana (DRAS; CHIANG; SCHULER, 2004), a GC tende a representar as relações sintagmáticas em termos de encaixamento hierárquico de constituintes. Nesse sentido, uma expressão como "quebrar a cara" será representada como [SUJ [QUEBRAR A CARA]], de

${ }^{6}$ Por exemplo, os padrões SUJ QUEBRAR OBJ e SUJ CORTAR OBJ se conectam, por um link vertical, ao padrão mais abstrato SUJ V OBJ. modo que a vinculação entre verbo e objeto, por exemplo, fica sugerida pelo fato de eles comporem uma mesma unidade sintática, em vez de ser explicitamente capturada por setas ou linhas que conectam os itens lexicais, como tipicamente se vê 
no formalismo das "gramáticas de dependência" (dependency grammars) - e também no CLG.

Por fim, é preciso reconhecer que os estudos construcionistas não exploram a sugestão saussuriana de que o valor de cada unidade do sistema emana das relações opositivas que elas contraem entre si. Em outras palavras, embora a GC reconheça que as construções gramaticais estão interconectadas, a concepção imanentista de valor, tão característica do pensamento saussuriano, está ausente das suas reflexões teóricas.

Estamos, portanto, diante de um panorama complexo, que pode ser sintetizado como segue. Em uma primeira aproximação entre a rede de construções e o sistema de signos, é possível reconhecer quatro tipos de laços: as relações verticais e horizontais, no primeiro caso; e as relações sintagmáticas e paradigmáticas, no segundo. Nesse conjunto, só há correspondência clara entre as relações paradigmáticas e os links horizontais. De resto, a exclusão das relações verticais no pensamento saussuriano decorre da própria definição de signo, ao passo que as "solidariedades sintagmáticas" são capturadas na GC por meio de relações hierárquicas de constituência.

\section{Premissa 4: Construções gramaticais devem ser combinadas entre si, a fim de produzir enunciados concretos}

A GC assume que construções mais concretas e mais abstratas devem ser combinadas entre si, a fim de que sejam produzidos enunciados reais. Assim, um padrão semiabstrato como LOGO SN pode receber, no slot nominal, um amplo conjunto de SNs, resultando em enunciados como "Logo eu!", "Logo o meu pai!" ou "Logo esse livro".

Interessantemente, essa sugestão também está presente no CLG. Em especial, a passagem abaixo soa particularmente (e, talvez, surpreendentemente) familiar para pesquisadores que tenham alguma intimidade com os princípios teóricos da GC:

No momento em que pronunciamos a frase "que lhe disse?" (a você), fazemos variar um elemento num tipo sintagmático latente, por exemplo, "que te disse?" - "que nos disse?" etc., e é por isso que nossa escolha e fixa no pronome the. (SAUSSURE, 2006 [1916], p. 151) 
Nessa passagem, descreve-se um "procedimento de fixação e de escolha" (SAUSSURE, 2006 [1916], p. 151) por meio do qual "fazemos variar" o elemento que preencherá uma posição em aberto em um "tipo sintagmático latente". Como discutimos mais acima, esse "tipo" equivale à noção construcionista de construção (semi)preenchida: trata-se de generalizações abstratas (ou parcialmente abstratas) que capturam a estrutura comum a diversas "recordações concretas" (SAUSSURE, 2006 [1916], p. 145).

A julgar pela passagem transcrita acima, o "tipo" abstrato que pode ser inferido dos exemplos "que lhe disse?", "que te disse?" e "que nos disse?" é algo como QUE PRONOME DISSE?. Dado esse "tipo latente", temos a possibilidade de inserir, em sua única posição fonologicamente aberta, diferentes elementos pronominais - nos termos do CLG, "fazemos variar" o pronome que irá concretizar o padrão geral.

A nosso ver, a semelhança entre esse mecanismo e o processo de combinação de construções é autoevidente: "variar" um item em um "tipo latente" equivale a alterar a construção concreta a ser inserida em uma construção abstrata. Tanto a GC quanto o CLG reconhecem, portanto, não apenas a existência de unidades concretas e abstratas como a possibilidade de que os elementos concretos preencham slots abertos nos "tipos gerais".

\section{Premissa 5: Não existe distinção qualitativa entre léxico, morfologia e sintaxe}

Como vimos na seção anterior, a literatura construcionista costuma fazer referência a um "continuum léxico-sintaxe". Essa expressão evoca a proposta de que o conhecimento linguístico deve ser concebido com um vasto repositório de construções, que inclui indistintamente palavras, morfemas, estruturas morfológicas, esquemas sintáticos e padrões prosódicos. Sob essa perspectiva, como se vê, não faz qualquer sentido assumir a existência de fronteiras rígidas entre léxico, morfologia e sintaxe.

Interessantemente, uma sugestão muito semelhante é desenvolvida no CLG. Para Saussure (2006 [1916], p.156-159), a única maneira "racional" de organizar o sistema linguístico consiste em tomar como base os dois tipos de relações que o sustentam: as relações sintagmáticas e paradigmáticas. Por essa 
razão, o $C L G$, assim como a $G C$, argumenta contrariamente às "divisões tradicionais" da Gramática em termos de "níveis" ou "componentes" como léxico, morfologia e sintaxe.

Essa posição, diga-se, não surpreende. Como vimos, as relações sintagmáticas e paradigmáticas se aplicam igualmente a itens morfologicamente complexos e a combinações sintáticas. Ora, se esses mecanismos são, por assim dizer, insensíveis ao tipo de signo, atuando indistintamente sobre palavras ou sequências de palavras, decorre daí que a distinção entre léxico, morfologia e sintaxe é meramente “ilusória" (SAUSSURE, 2006 [1916], p. 157).

A convergência entre o CLG e a CG neste ponto parece decorrer da concepção comum de língua como sistema. Com efeito, dada a metáfora de língua como uma espécie de teia de elementos entrelaçados, todas as unidades linguísticas terão em comum o próprio fato de funcionarem como as partes que compõem o todo. Diante disso, o fato de que alguns desses elementos possam pertencer ao domínio tradicional da morfologia e outros estejam associados à sintaxe importa pouco - o que realmente conta é seu papel como unidades constitutivas da "totalidade solidária".

\section{Considerações finais}

Conforme explicitado anteriormente, abordagens teóricometodológicas posteriores ao estruturalismo saussuriano apresentam questionamentos relevantes ao pensamento do genebrino - ou às imprecisões presentes no Curso de Linguística Geral, justificadas em parte pela própria característica da obra -, bem como relações intrínsecas com alguns dos postulados ali expostos, como se pode observar no modelo da Gramática de Construções. No intuito de trazer à tona tais relações, claras, mas pouco mencionadas na literatura ou circunscritas às unidades da língua tidas como fundamentais para cada uma das abordagens, a saber: o signo linguístico e a construção gramatical, pretendemos no presente artigo delinear as afinidades entre a GC e o modelo proposto no CLG, bem como algumas possíveis divergências entre essas duas abordagens. Discutimos, então, dentre outros pontos, a concepção de língua como rede construcional, contrapondo-a à noção de língua como um sistema de signos linguísticos, tal como proposta 
por Saussure, e focalizamos o tratamento da criatividade linguística pela GC e pelo CLG.

Esperamos, com isso, ter contribuído para a discussão sobre as relações (sejam por convergência, sejam por divergência) acima mencionadas entre o modelo estruturalista saussuriano e a abordagem construcionista, reconhecendo que há ainda muito a se propor em termos de aproximação de ambos os paradigmas. Nesse sentido, o artigo não pretende encerrar a questão; ao contrário, mostra-se como um ponto de partida para posteriores reflexões sobre esta temática.

\section{REFERÊNCIAS}

AKARI, N. Saussure and Chomsky - Langue and I-language. Bulletin of the Hiroshima Institute of Technology, Hiroshima, research vol. 49, p. 1-11. 2015.

BOUQUET, S. Introdução à leitura de Saussure. São Paulo: Cultrix, 1997.

BYBEE, J. Language, usage and cognition. Cambridge: CUP, 2010.

CHEN, R. English inversion: A ground-before-figure construction. Berlin/New York: Mouton de Gruyter, 2003.

CHOMSKY, N. Aspects of the theory of syntax. Cambridge, Massachusetts, The MIT Press. 1965.

DIESSEL, H. Usage-Based Construction Grammar. In: DABROWSKA, E.; DIVJAK, D. Handbook of Cognitive Linguistics. Berlin: Mouton de Gruyter, 2015.

DABROWSKA, E. Recycling utterances: a speaker's guide to sentence processing. Cognitive Linguistics, v. 45, n. 4, p. 617653, 2014.

DURKHEIM, E. As regras do método sociológico. São Paulo: Edipro, 2012.

DRAS, M.; CHIANG, D.; SCHULER, W. On relations of constituency and dependency grammars. Research on language and computation, 2, p. 281-305, 2004. 
FILLMORE, C. J. Innocence: a second idealization for linguistics. Proceedings of the Fifth Annual Meeting of the Berkeley Linguistics Society, p. 63-76, 1979.

GOLDBERG, A. E. Constructions at work: the nature of generalization in language. Oxford: Oxford University Press, 2006.

; AUWERA, J. V. D. This is to count as a construction. Folia linguistica, v. 46, n. 1, p. 109-132, 2012.

GORDON, W. Langue and Parole. In: SANDERS. The Cambridge Companion to Saussure. Cambridge Companions online: Cambridge University Press, p. 76-87. 2006.

GRAFII, G. 200 years of syntax: a critical survey. Amsterdam and Philadelphia: John Benjamins. 2001.

HARRIS, R. \& TAYLOR, J. Landmarks in linguistic thought I - The Western tradition from Socrates to Saussure. London \& New York: Routledge, 2007, $2^{\text {a }}$ edição.

HOFFMANN, T.; TROUSDALE, G. The Oxford Handbook of Construction Grammar. Oxford: OUP, 2013.

HOLDCROFT, D. Saussure: signs, system, and arbitrariness. New York: Cambridge University Press, New York. 1991

HUDSON, R. Language Networks: The New Word Grammar. NY: Oxford University Press, New York. 2007.

ILARI, R. O estruturalismo linguístico: alguns caminhos. In: MUSSALIM, F.; BENTES, A. C. (Orgs). Introdução á linguística: fundamentos epistemológicos. São Paulo: Cortes, 2004.

MATTHEWS, P. A short story of structural linguistics. Cambridge: CUP, 2003.

RIZZI, L. Some Elements of Syntactic Computations. In: BICKERTON \& SZATHMÁRY. Biological Foundations and Origins of Syntax. Cambridge, Massachusetts, London, England: The MIT Press. 2009.

SAUSSURE, F. Curso de Linguística Geral. São Paulo: Cultrix, 2006. 


\begin{abstract}
From sign to construction: the Saussurean legacy and the constructionist approaches of grammar

The importance of Ferdinand de Saussure's propositions, presented in the Course in General Linguistics (CLG), to the establishment of the basis of so-called Modern Linguistics is a consensus among linguists. Nevertheless, there is none or just a few recognition of the echoes of the grammatical reflections presented in CLG on the theoretical model of Construction Grammar (CG), developed in the United States at the end of the twentieth century. Therefore, this article aims: (i) to show how CG offers an eminently Saussurean way to overcome the gap left by the CLG regarding the treatment of syntactic creativity and (ii) to evaluate the convergence - and eventual divergences - between the CG and the grammar model outlined in the CLG. We expect to contribute to a reappraisal of the extension of Saussure's legacy on contemporary grammatical theorization, recognizing him as an (unlikely?) precursor of Construction Grammar.
\end{abstract}

Keywords: Linguistic sign. System. Constructions. Constructional network. Construction Grammar. 